\title{
Investigation and Protection Strategy of Water Resources Cultural Heritage
}

\author{
Deng Jun ${ }^{1,2, a}$, Lv Juan ${ }^{1,2}$, Liu Jiangang ${ }^{1,2}$, Zhou Bo ${ }^{1,2}$, Li Yunpeng ${ }^{1,2}$ \\ ${ }^{1}$ Institute of Water Conservancy History of China Institute of Water Resources and Hydropower Research, Beijing, 100038, China \\ ${ }^{2}$ Research Center on Flood Control, Drought Control and Disaster Mitigation of the Ministry of Water Resources, Beijing, 100038, \\ China
}

\begin{abstract}
Based on the first national water cultural heritage survey of existing water conservancy, this paper sorts cultural heritage status quo and the main problems; through the status and value analysis, protection strategy recommendations are proposed.
\end{abstract}

\section{Research Background}

In the Notice of Strengthening the Protection of Cultural Heritages (Guo Fa [2005] No.42) issued by the State Council in 2005, it was demanded that all departments should fully recognize the importance of protecting cultural heritages and effectively do a good job in this regard. The Sixth Plenary Session of the Seventeenth CPC Central Committee held in 2011 called on the entire Party and the Chinese people to raise a new upsurge in socialist cultural construction and promote the great development and great prosperity of socialist culture. Conducting the research on water from the cultural perspective and reexamining the relationship between humans and water have captured extensive attention.

Deng Jun: dengj@iwhr.com

In response to the call of the State Council to strengthen the protection of cultural heritages, the Ministry of Water Resources issued the Official Written Reply to the Task Plan for Protecting the Ancient Water Resources Projects in Use and Water Resources Heritages (Shui Gui Ji [2009] No.204) in 2009, entrusting China Institute of Water Resources and Hydropower Research to map out the plan for overall protection of the ancient water resources projects in use and water resources heritages.

To have a systematic understanding of the status quo and the problems of ancient water resources projects in use and water resources heritages all over the country and to provide basic support for the formulation of the protection plan, the General Office of the Ministry of Water Resources issued the Notice of Surveying the Ancient Water Resources Projects in Use and Water Resources Heritages (Ban Gui Ji [2010] No.11) in January 2010 for conducting a preliminary survey of water resources cultural heritages across the country for the first time. Based on the works done by the project team, this article plans to discuss the strategy of protecting water resources cultural heritages in light of the preliminary results obtained through the survey of the present situation.

\section{Investigation situation}

For the purpose of this paper, the water resources cultural heritages mainly refer to ancient water resources projects that have historical, cultural, scientific and technological value. They also include the relevant heritages subject to the administration of the water resources departments, such as tablet inscriptions, folklores, village regulations and folk conventions for maintaining the operation of water resources projects, and folk customs developed in the process of production practices ${ }^{[1]}$.

The water resources projects built prior to 1911 and water resources heritages fell into the scope of the survey, mainly including irrigation projects, flood control works, urban water conservancy facilities, water systems in gardens and parks, water transportation projects, water and soil conservation projects, hydropower projects, water supply and drainage projects, seawall projects and hydraulic projects, with the ancient water resources projects in use as the key points of survey and research. The timeframe of the water resources projects and heritages having important historical and cultural influences and under the survey was extended to 1949. The survey focused on the following six aspects: locations of projects, types of projects, the periods of time when the construction was initiated, the status quo of preservation and utilization, the administrative departments, and existing problems. Table 1 shows further details. 
Table 1. Survey items of ancient water resources projects in use and water resources heritages

\begin{tabular}{|c|c|}
\hline Survey category & concrete contents \\
\hline Locations of projects & $\begin{array}{r}\text { Irrigation engineering, flood control engineering, } \\
\text { urban water conservancy, garden water } \\
\text { conservancy, water transportation engineering, soil } \\
\text { and water conservation engineering, hydropower } \\
\text { engineering, water supply and drainage engineering, } \\
\text { seawall engineering and hydraulic engineering }\end{array}$ \\
\hline Types of projects & $\begin{array}{c}\text { In use } \\
\text { Historical remains } \\
\text { Ruins }\end{array}$ \\
\hline Starting time & \\
\hline Management status & \\
\hline Problems & \\
\hline
\end{tabular}

The survey was started through correspondence with each province as a unit. Based on the results of survey through correspondence, field survey was conducted on projects that had significant influences. Relevant materials obtained from historical records of water resources projects built on rivers would be used to supplement the obviously missing information about these projects and heritages. The survey results confirmed that there were 584 ancient water resources projects and heritages in 379 locations. These projects and heritages include two world cultural heritages, 33 major historical and cultural sites under state protection and 47 major historic and cultural sites under provincial-level protection.

\section{Value Assessment}

Water resources cultural heritages come in a variety of types. In addition to the roles of ancient water resources projects in use in flood control, irrigation and power generation, these heritages have multiple values in history, science and technology, culture, economy, ecology and tourism.

\subsection{Historical and cultural value}

A history of the Chinese civilization is also a history of the civilization of water resources. Like the history of the Chinese civilization, the history of water resources has run a long course from a remote source. By using diverse natural resources, people having inhabited the land of China have created, developed and managed many water resources project systems that have distinctive characteristics through production practices and in light of local conditions. These ancient water resources projects that were built based on using the local knowledge and traditional experience are still in use, displaying superb workmanship excelling nature and fully reflecting the diversity of humans and their cultures and the evolution of the profound relationships between humans and natural environment.

In China, modern water resources projects have not yet exceeded ancient water resources projects in some respects that reflect the rich cultural values of ancient water resources projects, such as theories of water rights and cultural connotations of water resources management. The application of modern Western water rights and conceptual water rights was vividly expressed in the water resources management practices in ancient China. For instance, the Rules on Water Resources Management (Shuibu shi) was issued during the Tang Dynasty (AD 618-907) as the national rules on water resources. These rules first asserted the national rights on Zhengbai Canal in the form of law. In other words, Zhengbai Canal would first be used to meet the needs of irrigation, followed by the needs of food processing such as building water mills and water-powered rollers for grinding grain. Likewise, village regulations and folk conventions also set strict stipulations upon water rights, thus maintaining the normal operation of water resources projects ${ }^{[2]}$. Complete rural autonomous organizations existed in the regions where water resources projects were maintained. Water management and water administration contributed to the close link between water and the society as well as culture. Corresponding cultural phenomena emerged, such as the worship of the deity of water, which were reflected in the appearance of magnificent religion-themed buildings such as Erwang Temple, Dragon Taming Temple, and Palace of King Yu. The cultural value of ancient water resources projects is reflected in its continuation in history, its integration with local habits, religions and architectural culture and the interactions between them.

\subsection{Scientific and technological value}

The ancient water resources projects in use were built in light of the shape of rivers and hydrologic conditions within the local regions, and hence they have enjoyed quality landscape environment, inhabitation environment and ecological environment. From planning to construction, the ancient water resources projects in use largely display the characteristics that they have been integrated with natural environment and that they have been constantly improved following the changes of natural environment. For instance, dam-less water diversion is the most basic architectural form of ancient Chinese water resources projects. Such a way of water diversion makes full use of river hydrologic conditions and topographic 
characteristics, so that water resources projects can meet the needs of water diversion, flood control and navigation while making no change to the original natural characteristics of rivers. At present, as the use of freshwater approaches the upper limit, rivers and lakes gradually shrink in size, water environment and the ecology of water deteriorate day by day, and biodiversity disappears bit by bit. With the sudden appearance of water crisis in all respects, people attach increasing importance to the planning and designing philosophy of "achieving harmony between humans and the nature" which is seen in the ancient water resources projects in use.

\subsection{Social and economic value}

The ancient water resources projects in use still play the roles of flood control, irrigation and power generation, creating tremendous social and economic benefits.

With their skillful layout, the ancient water resources projects in use have comprehensive functions of preventing drought, controlling flood, irrigating farmland, facilitating daily life and beautifying the environment. The distribution of these projects also displays a special kind of culture in ancient society. For instance, many places become well-known scenic spots because of the locally built water resources projects and reservoirs. Some water resources projects enjoy worldwide fame, such as Xin'anjiang Reservoir in Zhejiang Province and the Ming Tombs Reservoir in Beijing. In some other places, the development of water culture promotes the appearance of tourist hotspots, such as Wuzhen Water Town and the ancient town of Xitang in Jiaxing, Zhejiang Province. Still other places present colorful natural landscape. A case in point is Hani Rice Terraces system in Yunnan Province[3]. It is a typical water resources project that embodies a compound ecological system and represents the perfect integration of farming culture with customs of ethnic minorities.

\section{Status Quo and Main Problems}

According to survey results, the water resources cultural heritages are faced with the following four kinds of difficult situations as a result of the vast land of China and the long-term lack of administration over ancient water resources projects and heritages:

(1) Traditional form of water resources projects that are commensurate with local natural characteristics and river features is on the verge of disappearance. The ecological environment, values on water and cultural forms are degenerating.

A typical case in point is karez, a traditional irrigation system of wells connected by underground channels commonly seen in Turpan, Xinjiang. Karez is a traditional form of water resources projects unique to the oases in Xinjiang. There were about 1,784 karez prior to the 1950 s. Only 614 karez were left in 2003 after 1,170 karez were dried up; and such a number was further reduced to 427 in 2009[4]. Most karez were abandoned following the fall of the underground water level in oases. This was mainly attributed to the blind development of pumping wells and the underground water exploration that was out of control. The price paid for the abandonment of karez is the destruction of a sound recycling mechanism of underground water at the Turpan Basin at the southern foot of the Tianshan Mountain. Another kind of destruction is the loss of a culture created by the karez irrigation system in drought areas. In other words, changes have taken place in the local inhabitants' values towards water which were based on the fact that they had to invest heavily in accessing water and maintaining the supply of water. Such changes lead to the disappearance of the cultural basis of equitable occupation of local water resources. Facts have proved that the recovery or partial recovery of local traditional forms of water resources projects in drought areas has important value for restoring the regional ecological environment.

(2) There is lack of specific protection of ancient water resources projects in urban planning, construction and administration. The constructive damages become a prominent problem.

For instance, since there is no natural river running through Beijing, the water system composed of rivers and lakes in Beijing is formed based on water resources projects. These projects were constantly constructed during the Yuan (1206-1368), Ming (1368-1644) and Qing (1644-1911) dynasties, forming an important component of the urban appearance of capital Beijing. However, more than two thirds of the length of the city moat was covered during the urban construction in the 1950s and 1960s[5]. The river courses of Tonghui River and Chang River were blindly widened and the dykes of these rivers were blindly heightened. As a result, the amount of water replaced and the evaporation loss were increased in these river courses. In addition, local rainwater could not converge and flow together into the rivers, thus damaging the cultural value of the river landscape. Most of the rivers and lakes in the city proper of Beijing were filled up, leading to the loss of venues for storing flood water. In recent years, Beijing suffers from waterlogging whenever there is a heavy rain.

(3) The ownership of the administration over some ancient water resources projects is unclear. As a result, these projects are in want of long-term administration and left to perish on their own.

At present quite a number of small water resources projects are subject to the administration at the level of towns or townships, or even villages. These projects are left to perish on their own as a result of the changes with the ownership of rural land and the lack of administration over the grass-root public facilities.

For instance, there were a number of rural water resources projects constructed at Anshun in Guizhou Province when garrison troops and peasants opened up waste land and grew food grain during the Ming Dynasty. The ownership of the local land was changed following the introduction of land contracting system in 1978, however. These small projects were nominally under the administration of local township water resources station, and did not fall into the scope of administration under the irrigated area. In fact, they were under no administration at all. As a result, most of the water resources projects that have a history of 500 years lose their effectiveness. Only 
a small number of them still maintain their functions under the administration of some villages where the awareness of patriarchal clan still prevails.

(4)The destructive damages done to the ancient water resources projects lead to the degeneration of the entire regional ecological environment.

Under the impacts of economic wave, the large-scale mining, real estate development and construction of business parks over the recent 10 years have inflicted unprecedented destructive damages to the ancient water resources projects located in cities or scenic spots.

For instance, the spring diversion project of Jin Temple was a project with a history of nearly 1,000 years in the region of Taiyuan, capital of Shanxi Province. The project was not only an important part of the scenic spots of Jin Temple, but also a part of infrastructure for local industrial and agricultural production and water provision in urban and rural areas. However, the large-scale coal mining intercepted the local aquifer, which caused the spring diversion project to lose all its effectiveness. As a result, the cultural landscape and natural environment of Jin Temple and its surrounding areas are seriously damaged.

\section{Summary}

With the large-scale modern construction of water resources projects, rapid social-economic development and the lack of knowledge about and recognition of the value of ancient water resources projects across all walks of life and even within the water resources industry, a large number of ancient water resources projects have been damaged, abandoned or replaced by new projects over the past decades at an ever-increasing speed. Intensifying the efforts to protect and reasonably utilize ancient water resources projects in use and water resources heritages admits no delay.

It is suggested to establish a comprehensive administration system from top to bottom at the levels of the State, provinces (autonomous regions and municipalities directly under the Central Government), prefecture-level cities and county-level cities and covering all river basins.

A steering committee for guiding the administration of ancient water resources projects and water culture heritages should be established. The office of the steering committee should be established at the General Office of the Ministry of Water Resources, and it is in charge of relevant administration works, with a secretariat established under it. The steering committee exercises vertical administration over ancient water resources projects in use and water resources heritages, organizes the formulation of necessary laws and regulations, establishes the national-level criteria for applying for and recognition procedures of ancient water resources projects in use and water resources heritages, and establishes protection administration systems at all levels to supervise the protection, administration and utilization of these projects and heritages.

Efforts should be made to issue regulatory documents such as Requirements for Formulating the Plans for Protecting Ancient Water Resources Projects in Use and
Water Resources Heritages and Plans and Standards for Protecting Ancient Water Resources Projects in Use and Water Resources Heritages to raise compulsory requirements for protecting ancient water resources projects in use. Special plans and procedures for submitting applications for approval concerning the renovation, expanded construction and construction of ancient water resources projects (the scope of such projects may be gradually extended to cover the modern projects having a history of more than 50 years) should be put in place, and these renovation projects should be subject to examination and approval in accordance with the procedures.

\section{Acknowledgments}

This work was supported by IWHR Research\& Develop ment Support Program (JZ0145B572016) and Program (J Z0145C242019).

\section{References}

1. Tan Xuming. Explanation of the definition, characteristics, type and value for water culture heritage. China Water Resources,2012, (21).

2. Deng Ren. Dujiangyan and hydraulic engineering ethics [J]. Journal of North China University of water resources and hydropower (SOCIAL SCIENCE EDITION), 2010,26 (04): 108-113

3. Yang Huilin, Lu Hanbing. Study on the transmission path of ecological culture in Hani terrace, the world cultural heritage [J]. Agricultural Archaeology, 2019 (03): 247-253

4. Su Chunyu, Li Chen, Wang Liheng. Study on coordinated strategy of Rural Revitalization and Karez protection in Turpan Oasis [J]. Small town construction, 2020,38 (01): 22-28

5. Ma Dongchun, Guo TianKuo. Water culture and urban development in Beijing [J]. Water conservancy development research, 2020,20 (08): 69-73 